NEUROENTEROLOGY

\title{
The role of glial cells and apoptosis of enteric neurones in the neuropathology of intractable slow transit constipation
}

\author{
G Bassotti, V Villanacci, C A Maurer, S Fisogni, F Di Fabio, M Cadei, A Morelli, \\ T Panagiotis, G Cathomas, B Salerni
}

See end of article for authors' affiliations

\section{Correspondence to:} Dr G Bassotti, Clinica di Gastroenterologia ed Epatologia, Via Enrico Dal Pozzo, Padiglione W 06100 Perugia, Italy; gabassot@tin.it

Revised version received 19 May 2005

Accepted for publication

7 June 2005

Published online first

24 July 2005

Background: Idiopathic slow transit constipation is one of the most severe and often intractable forms of constipation. As motor abnormalities are thought to play an important pathogenetic role, studies have been performed on the colonic neuroenteric system, which rules the motor aspects of the viscus.

Aims: We hypothesised that important neuropathological abnormalities of the large bowel are present, that these are not confined to the interstitial cells of Cajal and ganglion cells, and that the previously described reduction of enteric neurones, if confirmed, might be related to an increase in programmed cell death (apoptosis).

Patients and methods: Surgical specimens from 26 severely constipated patients were assessed by conventional and immunohistochemical methods. Specific staining for enteric neurones, glial cells, interstitial cells of Cajal, and fibroblast-like cells associated with the latter were used. In addition, gangliar cell apoptosis was evaluated by means of indirect and direct techniques. Data from patients were compared with those obtained in 10 controls.

Results: Severely constipated patients displayed a significant decrease in enteric gangliar cells, glial cells, and interstitial cells of Cajal. Fibroblast-like cells associated with the latter did not differ significantly between patients and controls. Patients had significantly more apoptotic enteric neurones than controls. Conclusion: Severely constipated patients have important neuroenteric abnormalities, not confined to gangliar cells and interstitial cells of Cajal. The reduction of enteric neurones may in part be due to increased apoptotic phenomena.

C hronic constipation is a symptom encountered frequently in clinical practice, and may affect a considerable percentage of the general population. ${ }^{1}$ Several mechanisms contribute to constipation, although the main two subgroups are related to obstructed defecation and slow transit. ${ }^{2}$ In particular, slow transit constipation (STC) usually represents the subgroup of patients with most severe symptoms who tend to be less influenced by therapeutic measures. ${ }^{3}$ These patients are frequently labelled as intractable, ${ }^{4}$ and the most severe ones (up to true colonic inertia) are often referred for a surgical approach. ${ }^{5}{ }^{6}$

The pathophysiological causes of STC are still poorly understood, and abnormal colonic motility is thought to play an important role. $^{78}$ Several qualitative and quantitative changes in the enteric nervous system of such patients have been described. They include abnormal enteric neurochemistry, ${ }^{9-12}$ decreased argyrophilic neurones, ${ }^{13}$ decreased intraganglionic neurofilaments, ${ }^{14}$ and hypoganglionosis of the myenteric plexus. ${ }^{15}$ More recently, a decrease in colonic interstitial cells of Cajal (ICC) in STC patients has also been reported. ${ }^{16-18}$

However, most of the above reports involved small groups of patients with different clinical and instrumental characteristics, and the studies usually focused on only one or two issues related to the myenteric plexus.

Here we report a neuropathological investigation of the colon in a relatively large and homogeneous group of STC patients. In particular, we wished to test the hypothesis that the abnormalities are not confined to the ICC and ganglion cells, and that the previously described reduction of enteric neurones, if confirmed, might be related to an increase in programmed cell death (apoptosis).

\section{PATIENTS AND METHODS \\ Patients}

Twenty six STC patients (25 women, one man; age range 2478 years) undergoing colectomy with ileorectostomy for severe intractable constipation were enrolled in the study. Inclusion criteria were: (1) longstanding history of constipation (more than three years; mean 14 (range 3-59)); symptoms arose in childhood in one patient and in later life in the others; (2) one or fewer evacuations per week; (3) absence of frequent (more than two episodes per month) or chronic abdominal pain; (4) sensation of incomplete evacuation in >1/4 defecations; (5) negative history for (sub)occlusive episodes; and (6) unresponsiveness to appropriate and intensive medical treatment, including high fibre diet, stimulant and osmotic laxatives, and enemas. Intestinal transit time, measured by means of radiopaque markers, was delayed in all patients (up to more than 240 hours). Causes of secondary constipation were excluded by drug history, physical examination, and laboratory screening (blood chemistry, thyroid hormones and, where appropriate, oral glucose tolerance test, sex hormone profiles, and antinuclear antibodies). To exclude organic diseases or mechanical causes of constipation and megacolon or megarectum, each patient underwent double contrast barium enema and/or colonoscopy. Absence of Hirschsprung's disease was demonstrated by normal relaxation of the internal anal sphincter at anorectal manometry. ${ }^{19}$ No patient had evidence of

Abbreviations: STC, slow transit constipation; ICC, interstitial cells of Cajal; NSE, neurone specific enolase; MAb, monoclonal antibody; PAS, periodic acid-Schiff 
obstructed defecation, as documented by anorectal manometry and/or defecography.

\section{Controls}

Ten patients (nine women, one man; age range $43-75$ years) undergoing left hemicolectomy for non-obstructing colorectal cancer were used as controls as there is evidence that the distribution of ICC is relatively uniform throughout the human colon. ${ }^{16}$ No data are available on the regional density of enteric neurones and glial cells in humans although in preliminary observations we did not detect significant regional differences between the various colonic segments, except in the rectum ( $G$ Bassotti and V Villanacci, personal observations). Control specimens were taken at least $5 \mathrm{~cm}$ from the resection margin in tumour free areas.

\section{Methods}

After removal, surgical specimens were immediately fixed in $10 \%$ neutral buffered formalin for 24 hours, and then 12-20 full thickness samples from the whole resected colon were taken and transversal sections obtained. For conventional histology, $5 \mu \mathrm{m}$ paraffin sections were stained with haematoxylin-eosin, periodic acid-Schiff (PAS), and trichrome stain.

\section{Immunohistochemistry}

At least 40 slides for each patient were processed for immunohistochemistry. To evaluate markers of the enteric nervous system we used monoclonal antibodies towards neurone specific enolase (NSE, NCL-NSE2, dilution 1:50; Novocastra Laboratories, Newcastle upon Tyne, UK) acting as a marker of gangliar cells, and the glial marker protein S100 (S-100, dilution 1:50; Dako, Carpinteria, California, USA) was used..$^{21}$ As ICC express Kit, ${ }^{22}$ an anti-Kit antibody (rabbit polyclonal antibody, IgG, dilution 1:50; Dako) was used to detect these cells, as previously reported..$^{23}$ Moreover, CD34 staining (CD34 clone QBEnd/10, dilution 1:30; Neo markers, Union City, California, USA) was used to evaluate the population of fibroblast-like cells which are intimately associated with the ICC. ${ }^{24}$ Two methods were used as markers for apoptosis in the enteric nervous system: (a) expression of Bcl-2 protein (BCL2 oncoprotein clone 124, dilution 1:10; DBS, Pleasantown, Australia), a proto-oncogene responsible for specific suppression of apoptosis in several important situations, ${ }^{25}$ and well displayed in human enteric neurones, ${ }^{26}{ }^{27}$ and (b) monoclonal antibody to single stranded $\mathrm{DNA}^{28}$ using the formamide monoclonal antibody (formamide-MAb) method (Mab F7-26 BMS 156; Bender MedSystem, Vienna, Austria) which detects apoptotic cells in tissue processed with routine histological techniques and allows discrimination of apoptosis from necrosis. ${ }^{29}$

NSE, S-100, CD34, and Bcl-2 immunostaining was carried out using a peroxidase based visualisation kit (Dako LSAB) following the manufacturer's recommendations. Diaminobenzidine tetrahydrochloride was used as chromogen. Slides were then counterstained with Mayer's haematoxylin for five seconds, dehydrated, and mounted in Clarion (Biomeda, Foster City, California, USA). To account for nonspecific staining, peptides that blocked polyclonal antibody bindings (passage with normal goat serum) were used, or sections were incubated in the absence of primary antibody. In these cases, no immunostaining was detected. For Bcl-2, expression in mucosal lymphoid cells served as an internal control.

\section{Expression of Kit}

Consecutive formalin fixed paraffin sections were dewaxed and rehydrated through decreasing alcohol series up to distilled water. Sections were then subjected to heat induced epitope retrieval by immersion in a heat resistant container filled with citrate buffer solution $(\mathrm{pH}$ 6.0) placed in a pressure cooker and microwaved for 20 minutes. Endogenous peroxidase activity was suppressed by incubation with $3 \%$ solution of $\mathrm{H}_{2} \mathrm{O}_{2}$ for five minutes. Kit immunostaining was carried out using a peroxidase based visualisation kit (Dako EnVision) following the manufacturer's recommendations. Kit positive mast cells served as an internal control.

\section{Anti single stranded DNA immunohistochemistry}

Sections $2-3 \mu \mathrm{m}$ thick were warmed overnight at $60^{\circ} \mathrm{C}$, then dewaxed and rehydrated through decreasing alcohol series up to distilled water. Thereafter, sections were incubated for five minutes in phosphate buffered saline with addition of $20 \%$ Tween 20 , followed by passage with proteinase K (Dako) for 20 minutes. Sections were then rinsed with distilled water and heated in $50 \%$ formamide prewarmed to $60^{\circ} \mathrm{C}$ for 20 minutes. After cooling, endogenous peroxidase activity was suppressed by incubation with a $3 \%$ solution of $\mathrm{H}_{2} \mathrm{O}_{2}$ for five minutes. Normal serum diluted 1:50 was applied for 10 minutes at room temperature, followed by anti-DNA MAb for 30 minutes, according to the manufacturer's recommendations. After that, sections were incubated at room temperature with secondary polymeric antibody for $20 \mathrm{~min}$ utes and $\mathrm{ABC}$ (Kit super sensitive non-biotin detection system; Menarini, Firenze, Italy) for 30 minutes. Finally, a five minute reaction in the dark with diaminobenzidine (BioOptica, Milano, Italy) was carried out, and sections were then counterstained with Mayer's haematoxylin for five seconds, dehydrated, and mounted in Clarion (Biomeda). Positivity was observed under the microscope as an intense brown reaction.

The presence of lymphocytes was assessed by means of a monoclonal mouse antihuman CD3 antibody (dilution 1:40; Dako Cytomation).

Colonic smooth muscle was evaluated by means of an anti$\alpha$-actin monoclonal antibody (dilution 1:100; Biogenex, San Ramon, California, USA).

\section{Data analysis}

All slides were coded and analysed blind by two pathologists. For NSE, S100, and CD3, as well as Bcl-2 and formamide$\mathrm{MAb}$ positive cells, both the submucosa and myenteric plexuses were taken into account by optical microscopy at $\times 20$ magnification (Olympus BX 40). For each patient, the number of immunopositive cells was calculated and expressed as the mean of cells on 10 well stained and well oriented microscopic fields for each region of interest. To be considered positive, the intensity of cell immunostaining in relation to possible background had to be from moderate to strong, as described previously. ${ }^{30}$

The density of ICC was graded, according to a previously described method, ${ }^{31}{ }^{32}$ after evaluation of 10 well stained and well oriented fields at $\times 20$ magnification. The three previously identified populations of ICC were taken into consideration $^{33} 34$ : IC-SM, along the submucosal surface of the circular muscle bundle; IC-MY, within the intermuscular space between circular and longitudinal muscle layers (myenteric region, which displays the highest yield of ICC in normal tissue ${ }^{161831}$ ); and IC-IM, within the muscle fibres of the circular and longitudinal muscle layers. Nucleated cells as well as Kit positive labelled elongated structures were considered for analysis. ${ }^{32}$

For CD34, the strength of immunostaining (graded as either present or severely depleted/absent, according to recently reported criteria $^{35}$ ) was calculated around the myenteric plexus, between the elements of the plexus, within the longitudinal and circular muscle elements. Care was 

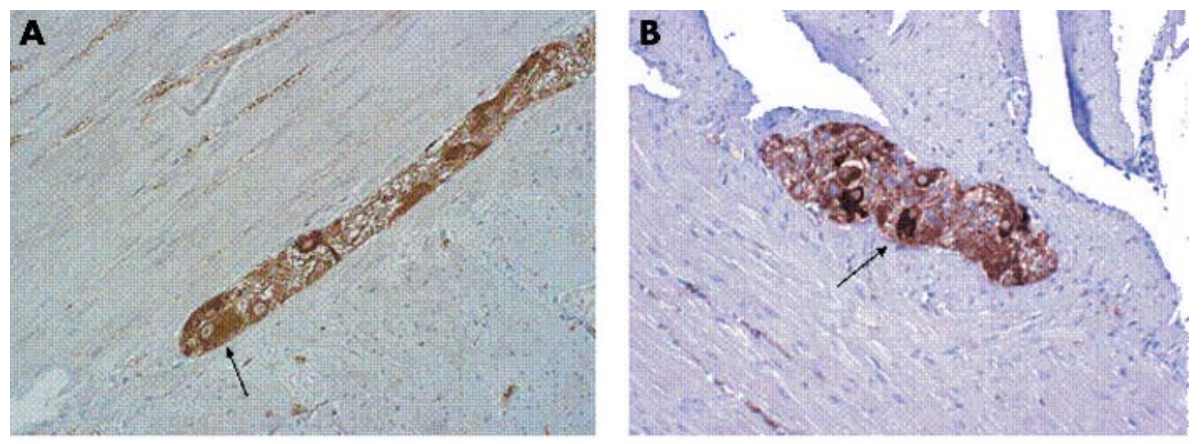

Figure 1 Neurone specific enolase expression in the myenteric plexus in a control subject $(A)$ and in a patient with slow transit constipation (B). The latter showed a decreased number of gangliar cells. Original magnification $\times 20$. Arrows indicate gangliar cells. S100 expression in a control subject (C) and in a patient (D), with the latter showing a reduction in glial cells. Original magnification $\times 20$. Arrow indicates glial cells.
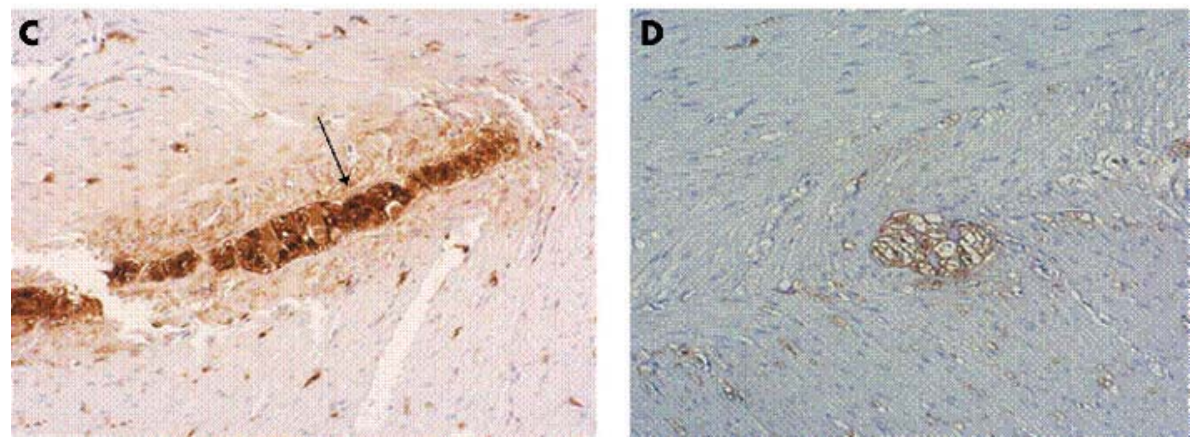

taken not to include vessels in the evaluation; however, the effectiveness of CD34 staining was indicated by the staining of capillaries in subjects with severe depletion/absence in other locations. ${ }^{35}$

\section{Statistical analysis}

The Komolgorov-Smirnov test for normality was applied and showed the data to be normally distributed. Data from controls and patients were thus compared using the Student's $t$ test for unpaired data (two tailed) and Pearson's correlation coefficient, where appropriate. Values of $\mathrm{p}<0.05$ were chosen for rejection of the null hypothesis. Data are expressed as means (95\% confidence interval).

\section{RESULTS}

\section{Conventional histology}

In both groups, the mucosa, submucosa, smooth muscle, and nerve plexus architecture appeared normal on haematoxylineosin, trichrome, and PAS staining. No inflammatory cells (or intranuclear or viral inclusions) were observed in or around muscular or nervous structures.

No patient exhibited hyperplastic changes (for example, giant ganglia) of the submucosal plexus, thereby excluding a diagnosis of intestinal neuronal dysplasia. ${ }^{36}$ Moreover, no inclusion body myopathy was found in smooth muscle. ${ }^{37}$ The presence of (pseudo) melanosis coli was shown in $80 \%$ of patients; those with a history of anthraquinone laxative use.

\section{Immunohistochemistry}

NSE expression (fig 1A, B) was significantly decreased in STC patients compared with controls, in both the myenteric (28.5 $(24-33) v 64.4(55-73)$ cells; $\mathrm{p}<0.001)$ and submucosal $(21$ $(19-24) \vee 58(46-70)$ cells; $\mathrm{p}<0.001)$ plexus. Similar results were detected for S100 expression (fig 1C, D), again significantly decreased in STC patients compared with controls in both the myenteric (174 (156-191) v 214 (190$238)$ cells, $\mathrm{p}=0.021)$ and submucosal (97 (85-109) $v 127$ (94-161) cells; $\mathrm{p}=0.026)$ plexus.

With regard to ICC (fig $2 \mathrm{~A}-\mathrm{C}$ ), a significant decrease was found in patients for IC-MY (141.3 (124-159) v 214 (154274) cells; $\mathrm{p}=0.0017)$ and IC-SM (14 (11-17) $v 29$ (23-35) cells; $\mathrm{p}<0.001)$ but not for IC-IM $(36(30-42) v 38(32-44)$ cells; $\mathrm{p}=0.68)$. Scattered Kit positive mast cells were observed in patient mucosa, and were numerically distributed as in control tissue.

No relationship was found between the number of myenteric neurones or ICC-MY and duration of constipation (for myenteric neurones $r=-0.02, \mathrm{p}=0.89$; for ICC-MY $r=0.156, \mathrm{p}=0.44$ ).

No differences between the groups were found in expression of CD34 (fig 2D), which was severely depleted/absent in two patients and two controls $\left(\chi^{2}\right.$ test, $\left.\mathrm{p}=0.66\right)$.

Expression of Bcl-2 (fig 3A, B) was significantly decreased in STC patients compared with controls, in both the myenteric (124 (108-141) v 167 (127-207) cells; $\mathrm{p}=0.015)$ and submucosal $(30(26-33) v 55.4(47-64)$ cells; $\mathrm{p}<0.001)$ plexus. Expression of Bcl-2 in mucosal lymphoid cells of patients was comparable with that found in controls.

The number of apoptotic enteric neurones (fig 3C, D) was significantly increased in the myenteric plexus of STC patients $(18(15-20) \vee 11(7-14)$ cells; $p=0.0052)$ whereas no differences were found in the submucosal plexus (16 (1219) $v 12(9-15)$ cells; $\mathrm{p}=0.15)$.

No lymphocytic infiltration (assessed by CD3) was observed in either the submucosal or myenteric plexus of patients or controls.

All patients and controls showed strong intensity for $\alpha$-actin immunostaining so that colonic smooth muscle was judged to display normal characteristics.

\section{DISCUSSION}

This study, carried out in a homogeneous and relatively large group of patients with severe and intractable STC, showed that abnormalities of the enteric nervous system are present in such patients but that they are not confined to neurones and ICC. Although a significant decrease in enteric neurones and ICC was found in patients compared with the control group, a further significant decrease was discovered in patients concerning glial cells, which were reduced in both the myenteric and submucosal plexus. We consider this finding interesting and worthy of comment. 

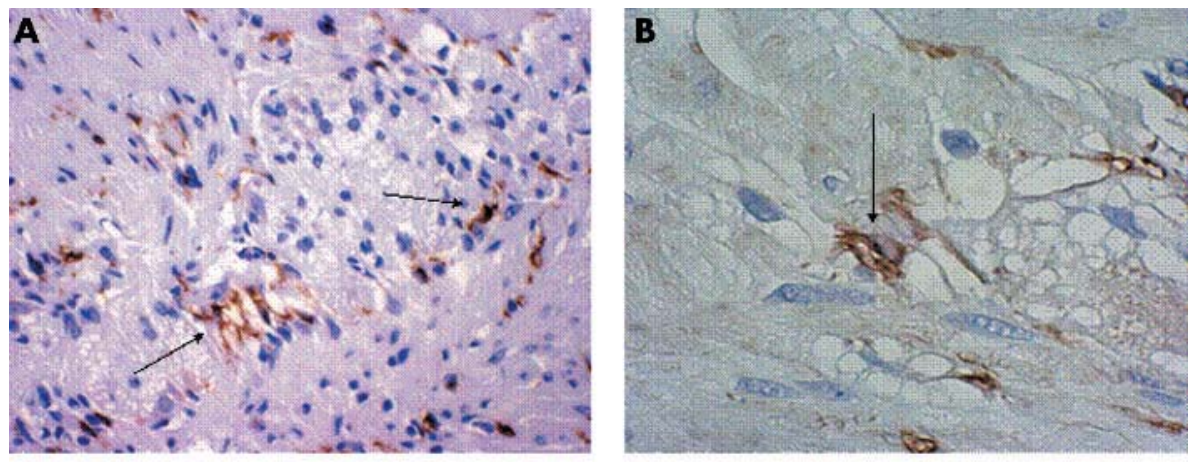

Figure 2 CD1 17 expression in a control subject (A, B) and in a patient with slow transit constipation (C). Note the decrease in interstitial cells of Cajal (ICC) in the patient's tissue. Original magnifications $\times 40(\mathrm{~A}, \mathrm{C})$ and $\times 100$

(B). ICC are indicated by arrows.

(D) CD34 expression in a patient.

Original magnification $\times 20$.
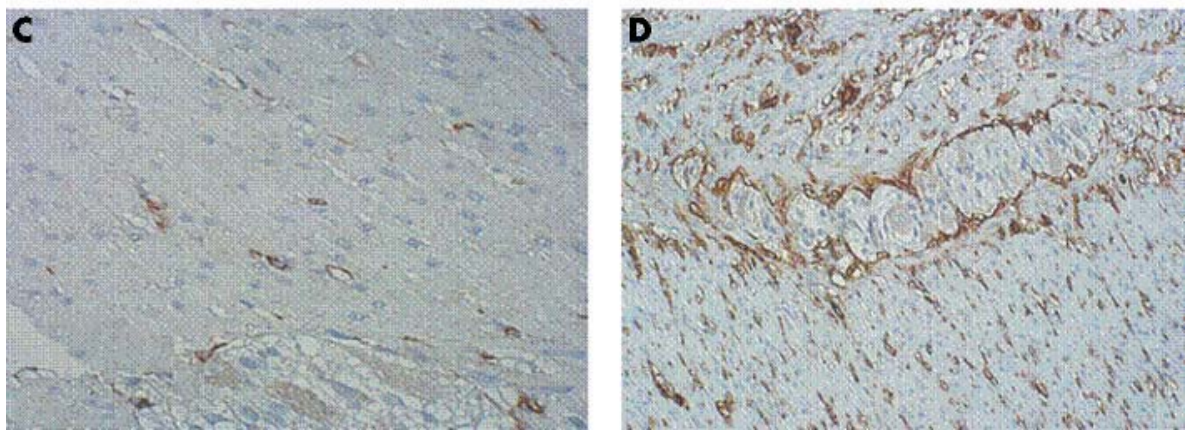

Enteric glial cells originate from the neural crest and provide support for neuronal elements. ${ }^{38}$ The best known function of the glia in the adult is the formation of myelin sheaths around axons, thus allowing the fast connections essential for nervous system function. The glia also maintains appropriate concentrations of ions and neurotransmitters in the neuronal environment. An increasing body of evidence indicates that glial cells are essential regulators of the formation, maintenance, and function of synapses, the key functional units of the nervous system. ${ }^{39}$ Thus as enteric glial cells are thought to act as intermediaries in enteric neurotransmission, ${ }^{40}$ their decrease might further weaken the already precarious neuroenteric balance due to the decrease in neuronal elements and ICC found in STC patients (see below). We are as yet unable to explain this decrease in glial elements in our patients, and there is no literature support, except for the reduction of these cells found in aged rats. ${ }^{41}$ However, no such reduction was detected in the similarly aged control group; it therefore appears unlikely that the decrease was due to aging, at least in the proportions we found.

Our patients presented with a significant drop in ICC in the myenteric and submucosal plexus. This finding is consistent with recent studies ${ }^{16-18}$ which also detected decreased ICC
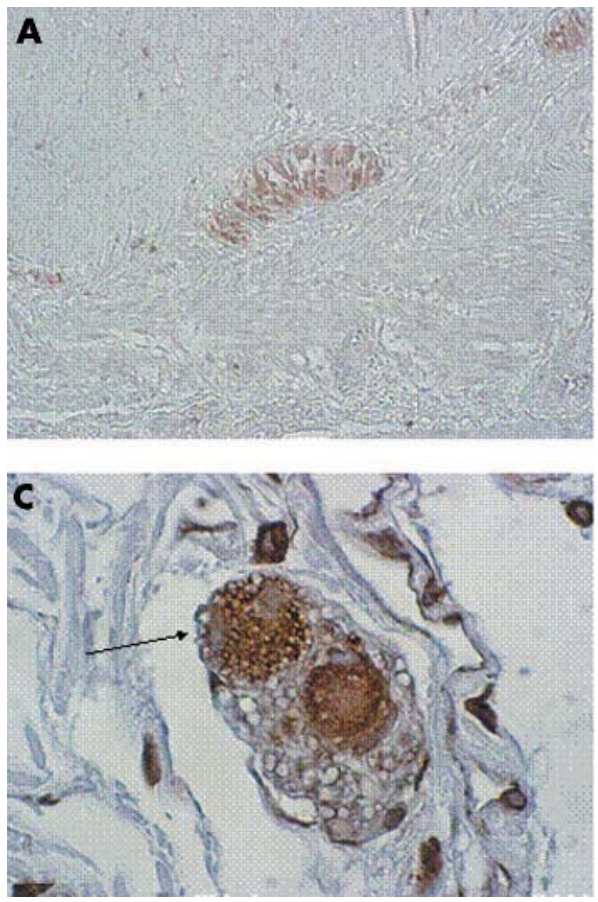
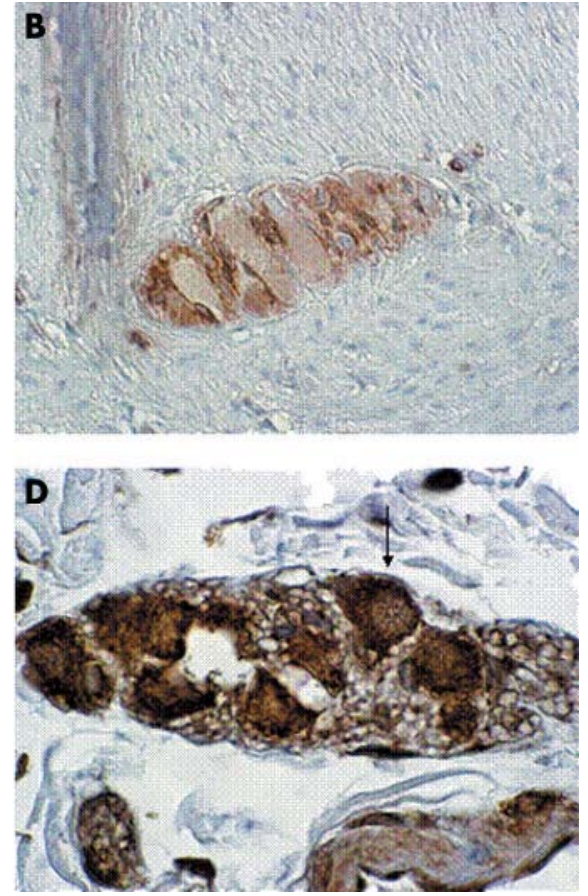

Figure $3 \mathrm{Bc} 2$ expression in a control subject $(A$, original magnification $\times 20)$ and in a patient with slow transit constipation ( $B$, original magnification $\times 40$ ). Apoptotic neurones (arrows) in a control subject $(C)$ and in a patient (D). Original magnification $\times 40$. 
volume in STC patients. ${ }^{42}$ The role of ICC as intestinal pacemakers has been clearly established in experimental animal models, which have shown that a lack of ICC networks leads to absence of slow waves and is accompanied by delayed or absent intestinal motility. ${ }^{43} 44$ Therefore, reduction or loss of ICC function might decrease or eliminate colonic electrical slow wave activity, thereby reducing the contractile response and resulting in delayed transit in STC patients. How can this finding be explained? Very recent evidence has shown that expression of c-kit mRNA and c-kit protein was significantly decreased in STC patients, suggesting that alterations in the c-kit signal pathway may play an important role in ICC reduction in such patients. ${ }^{45}$

The reduction in ICC was not accompanied by loss of CD34 positive fibroblasts, as observed in other pathological conditions. ${ }^{35}$ In a mouse model, blockage of Kit receptors caused transdifferentiation of intestinal ICC to a smooth muscle phenotype ${ }^{46}$; it is tempting to speculate that this inherent plasticity between ICC and smooth muscle cells might also occur in the human colon. If verified, this hypothesis could be exploited because, if ICC do not die in STC but rather redifferentiate, it may be possible to create conditions that would shift the phenotype back towards ICC.

A third important neuropathological aspect is loss of enteric neural elements found in these patients. Similar findings have previously been reported in small groups of STC patients ${ }^{15}{ }^{17}$ although not consistently. ${ }^{47}$ As the mechanisms that lead to depletion of enteric neurones are unknown, we tested the hypothesis that neuronal loss might be due to an increase in programmed cell death (that is, an apoptotic phenomenon).

Therefore, we first obtained indirect evidence by assessing Bcl-2, a unique proto-oncogene localised to mitochondria and able to block apoptosis in a variety of in vitro and in vivo situations, suggesting interference with a central mechanism of apoptosis. ${ }^{48}{ }^{49}$ Expression of Bcl-2 was significantly lower in the enteric neural elements of STC patients compared with controls, in both the myenteric and submucosal plexus, thus suggesting impairment of antiapoptotic factors.

Then we assessed apoptosis directly in enteric neurones by means of the formamide-MAb method, a technique unaffected by DNA breaks and able to identify apoptotic cells and to discriminate between them and necrotic cells. ${ }^{29}$ We found that the number of apoptotic enteric neurones in patients was significantly increased in the myenteric (but not in the submucosal) plexus, suggesting that apoptosis probably plays a role in loss of these cells. It is also worth noting that there is some literature evidence suggesting that, at least in colonic epithelia, melanosis coli may be a non-specific marker of increased apoptosis. ${ }^{50}$ These data did not however include submucosal or myenteric plexus evaluation.

Neuronal depletion further supports a role of the (deranged) enteric nervous system in the pathophysiology of STC. We feel that the overall findings from this study all point towards a synergic effect of each abnormality in causing abnormal colonic motor activity and, therefore, symptoms complained of by patients. A decrease in ICC impairs pacemaker activity, whereas loss of enteric glial cells and neurones reduces the nervous stimuli to effector (smooth muscle) cells, which are therefore unable to yield an effective and coordinated force able to carry out the main physiological purposes of the viscus, namely mixing, storage, and expulsion of the contents. The fact that the above abnormalities are incomplete (that is, there was not complete loss of any of the anatomical elements evaluated) may explain why residual colonic motor activity may be still detected in very severely constipated patients. ${ }^{5}{ }^{51}$

The causes of the abnormalities we documented are still unclear, and we have not found results supporting proposed pathophysiological mechanisms in late onset $\mathrm{STC}^{52}$ such as lymphocytic epithelioganglionitis ${ }^{53}$ and localisation of neurotropic viruses in the myenteric plexus. ${ }^{7}$

The study does have some limitations. For instance, the choice of controls and the (transverse) sectioning technique could be considered suboptimal. However, at least for children, there is some evidence that colonic transverse sections yield similar counts of neuronal density compared with longitudinal sections. ${ }^{54}$

In conclusion, patients with intractable "idiopathic" STC display important neuropathological enteric abnormalities, which are not confined to ICC and neuronal elements. Loss of the latter may be due in part to increased apoptosis, and this observation may be of some interest in the light of future therapeutic approaches aiming to reduce this phenomenon. Lastly, ever increasing knowledge of the basic mechanisms of this entity might in the future help to delete "idiopathic" from the definition of this form of constipation.

\section{Authors' affiliations}

G Bassotti, A Morelli, Department of Clinical and Experimental Medicine, University of Perugia, Italy

V Villanacci, S Fisogni, M Cadei, 2nd Department of Pathology, Spedali Civili, Brescia, Italy

F D Fabio, B Salerni, Department of Surgery, University of Brescia, Italy C A Maurer, T Panagiotis, Department of Surgery, Liestal Hospital, Switzerland

G Cathomas, Cantonal Institute of Pathology, Liestal Hospital, Switzerland

Conflict of interest: None declared.

\section{REFERENCES}

1 Stewart WF, Liberman JN, Sandler RS, et al. Epidemiology of constipation (EPOC) study in the United States: relation of clinical subtypes to socioeconomic features. Am J Gastroenterol 1999;94:3530-9.

2 Lembo A, Camilleri M. Chronic constipation. N Engl J Med 2003;349:1360-8.

3 Schiller LR. Review article: the therapy of constipation. Aliment Pharmacol Ther 2001; 15:749-63.

4 Camilleri M, Thompson WG, Fleshman JW, et al. Clinical management of intractable constipation. Ann Intern Med 1994;121:520-8.

5 Bassotti G, Chistolini F, Sietchiping Nzepa F, et al. Colonic propulsive impairment in intractable slow-transit constipation. Arch Surg 2003; 138:1302-4

6 Bassotti G, de Roberto G, Sediari L, et al. Toward a definition of colonic inertia. World J Gastroenterol 2004;10:2465-7.

7 Knowles $\mathrm{CH}$, Martin JE. Slow transit constipation: a model of human gut dysmotility. Review of possible aetiologies. Neurogastroenterol Motil 2000;12:181-96.

8 Bassotti G, lantorno G, Fiorella S, et al. Colonic motility in man: features in normal subjects and in patients with chronic idiopathic constipation. Am J Gastroenterol 1999;94:1760-70.

9 Koch T, Carney JA, Go VL. Idiopathic chronic constipation is associated with decreased colonic vasoactive intestinal peptide. Gastroenterology 1988;94:300-10.

10 Sjolund K, Fasth S, Ekman R, et al. Neuropeptides in idiopathic chronic constipation (slow transit constipation). Neurogastroenterol Motil 1997;9:143-50.

11 Faussone-Pellegrini MS, Infantino A, Matini P, et al. Neuronal anomalies and normal muscle morphology at the hypomotile ileocecocolonic region of patients affected by idiopathic chronic constipation. Histol Histopathol 1999; 14:1119-34.

12 Zhao RH, Baig MK, Mack J, et al. Altered serotonin immunoreactivities in the left colon of patients with colonic inertia. Colorectal Dis 2002;4:56-60.

13 Krishnamurti S, Schuffler MD, Rohrmann CA, et al. Severe idiopathic constipation is associated with a distinctive abnormality of the colonic myenteric plexus. Gastroenterology 1985;88:26-34.

14 Schouten WR, ten Kate FJ, de Graaf EJ, et al. Visceral neuropathy in slow transit constipation: an immunohistochemical investigation with monoclonal antibodies against neurofilament. Dis Colon Rectum 1993;36:1112-17.

15 Wedel T, Roblick UJ, OH V, et al. Oligoneural hypoganglionosis in patients with idiopathic slow transit constipation. Dis Colon Rectum 2002;45:54-62.

16 Lyford GL, He CL, Soffer E, et al. Pan-colonic decrease in interstitial cells of Cajal in patients with slow transit constipation. Gut 2002;51:496-501.

17 Wedel T, Spiegler J, Soellner S, et al. Enteric nerves and interstitial cells of Cajal are altered in patients with slow transit constipation and megacolon. Gastroenterology 2002;123:1459-67. 
18 Tong WD, Liu BH, Zhang LY, et al. Decreased interstitial cells of Cajal in the sigmoid colon of patients with slow transit constipation. Int J Colorect Dis 2004; 19:467-73

19 Phillips SF, Pemberton JH. Megacolon: congenital and acquired. In:Feldman M. Scharschmidt BF, Sleisenger MH.Gastrointestinal and liver disease, 6th edn. Philadelphia: WB Saunders Company, 1998:1810-19.

20 Krammer HJ, Karahan ST, Sigge W, et al. Immunohistochemistry of markers of the enteric nervous system in whole-mount preparations of the human colon. Eur J Pediatr Surg 1994;4:274-8.

21 Dzienis-Koronkiewicz E, Debek W, Sulkowska M, et al. Suitability of selected markers for identification of elements of the intestinal nervous system (INS). Eur J Pediatr Surg 2002;12:397-401.

22 Williams DE, Eisenman J, Baird A, et al. Identification of a ligand for the c-kit proto-oncogene. Cell 1990;63:167-74.

23 Horisawa M, Watanabe Y, Torihashi S. Distribution of c-Kit immunopositive cells in normal human colon and in Hirschsprung's disease. J Pediatr Surg 1998;33:1209-14.

24 Vanderwinden JM, Liu H, De Laet MH, et al. CD34+ cells in human intestine are fibroblasts adjacent to, but distinct from interstitial cells of Cajal. Lab Invest 1999:79:59-65.

25 Adams JM, Cory S. The Bcl-2 protein family: arbiters of cell survival. Science 1998;281:1322-6.

26 Wester T, Olsson Y, Olsen L. Expression of bcl-2 in enteric neurons in normal human bowel and in Hirschsprung disease. Arch Pathol Lab Med 1999; 123:1264-8.

27 De Giorgio R, Santini D, Ceccarelli C, et al. Defective expression of Bcl-2 in the enteric nervous system (ENS): a new potentially useful neuro-pathological marker for severe functional bowel disorders (FBD). Ital J Gastroenterol 1996:28(suppl 2):100.

28 Frankfurt OS, Robb JA, Sugarbaker EV, et al. Monoclonal antibody to singlestranded DNA is a specific and sensitive cellular marker of apoptosis. Exp Cell Res 1996;226:387-97.

29 Frankfurt OS, Krishan A. Identification of apoptotic cells by formamideinduced DNA denaturation in condensed chromatin. J Histochem Cytochem 2001;49:369-78

30 Maurer CA, Friess H, Buhler SS, et al. Apoptosis inhibiting factor Bcl-XL might be the crucial member of the $\mathrm{Bcl}-2$ gene family in colorectal cancer. Dig Dis Sci 1988;43:2641-8.

31 Hagger R, Gharaie S, Finlayson C, et al. Regional and transmural density of interstitial cells of Cajal in human colon and rectum. Am J Physiol 1998;38:G1309-16.

32 Bassotti G, Battaglia E, Bellone G, et al. Interstitial cells of Cajal, enteric nerves and glial cells in colonic diverticular disease. J Clin Pathol 2005:58:973-7.

33 Sanders KM. A case for interstitial cells of Cajal as pacemakers and mediators of neurotransmission in the gastrointestinal tract. Gastroenterology 1996:111:492-515

34 Ward SM, Sanders KM, Hirst GD. Role of interstitial cells of Cajal in neural control of gastrointestinal smooth muscles. Neurogastroenterol Motil 2004; 16(suppl 1):112-17.
35 Streutker CJ, Huizinga JD, Campbell F, et al. Loss of CD117 (c-kit)- and CD34-positive ICC and associated CD34-positive fibroblasts defines a subpopulation of chronic intestinal pseudo-obstruction. Am J Surg Pathol 2003; 27:228-35

36 Stoss F, Meier-Ruge W. Experience with neuronal intestinal dysplasia (NID) in adults. Eur J Pediatr Surg 1994:4:298-302.

37 Knowles CH, Nickols CD, Scott SM, et al. Smooth muscle inclusion bodies in slow transit constipation. J Pathol 2001;193:390-7.

38 Gershon MD, Rothman TP. Enteric glia. Glia 1991;4:195-204.

39 Jessen KR. Glial cells. Int J Biochem Cell Biol 2004;36:1861-7.

40 Ruhl A, Nasser Y, Sharkey KA. Enteric glia. Neurogastroenterol Motil 2004;16(suppl 1):44-9.

41 Phillips RJ, Kieffer EJ, Powley TL. Loss of glia and neurons in the myenteric plexus of the aged Fischer 344 rat. Anat Embryol (Berl) 2004;209:19-30.

42 He CL, Burgart L, Wang L, et al. Decreased interstitial cell of Cajal volume in patients with slow-transit constipation. Gastroenterology 2000;1 18:14-21.

43 Ward SM, Burns AJ, Torihashi S, et al. Mutation of the proto-oncogene c-kit blocks development of interstitial cells and electrical rhythmicity in murine intestine. J Physiol (Lond) 1994:480:91-7.

44 Huizinga JD, Thuneberg $L$, Kluppel $M$, et al. W/kit gene required for interstitial cells of Cajal and for intestinal pacemaker activity. Nature 1995;373:347-9

45 Tong WD, Liu BH, Zhang LY, et al. Expression of c-kit messenger ribonucleic acid and c-kit protein in sigmoid colon of patients with slow transit constipation. Int J Colorect Dis 2005;20:367-7.

46 Torihashi S, Nishi K, Tokutomi Y, et al. Blockade of kit signaling induces transdifferentiation of interstitial cells of Cajal to a smooth muscle phenotype. Gastroenterology 1999:117:140-8.

47 Park HJ, Kamm MA, Abbasi AM, et al. Immunohistochemical study of the colonic muscle and innervation in idiopathic chronic constipation. Dis Colon Rectum 1995;38:509-13.

48 Korsmeyer SJ. Bcl-2: an antidote to programmed cell death. Cancer Surv 1992;15:105-8.

49 Hockenbery DM. The bcl-2 oncogene and apoptosis. Semin Immunol 1992;4:413-20.

50 Byers RJ, Marsh P, Parkinson D, et al. Melanosis coli is associated with an increase in colonic epithelial apoptosis and not with laxative use. Histopathology 1997;30:160-4.

51 Bassotti G, Chiarioni G, Germani U, et al. Endoluminal instillation of bisacodyl in patients with severe (slow transit type) constipation is useful to test residual colonic propulsive activity. Digestion 1999;60:69-73.

52 Knowles $\mathrm{CH}$, Scott SM, Lunniss PJ. Slow transit constipation. A disorder of pelvic autonomic nerves? Dig Dis Sci 2001;46:389-401.

53 Lindberg G, Glia A, Nyberg G, et al. Lymphocytic epithelioganglionitis-a new entity causing severe motility disorders of the gut. Gastroenterology 1999; 116:G4476.

54 Smith VV. Intestinal neuronal density in childhood: a baseline for the objective assessment of hypo- and hyperganglionosis. Pediatr Pathol 1993;13:225-37. 